\title{
Influence of thymidylate synthase DNA polymorphisms and gender on the clinical evolution of patients with advanced colorectal cancer
}

\author{
MARIA-ENCARNACIÓN FERNÁNDEZ-CONTRERAS ${ }^{1,5}$, JOSÉ JAVIER SÁNCHEZ-HERNÁNDEZ ${ }^{3}$, \\ MERCEDES GUIJARRO ${ }^{2}$, JAVIER P. GISBERT ${ }^{1,5}$, NOA RIVAS ${ }^{2}$, MARÍA-LUISA GARCÍA DE PAREDES ${ }^{6}$, \\ ADOLFO HINOJAR-GUTIÉRREZ ${ }^{4}$ and CARLOS GAMALLO ${ }^{2,5}$
}

\begin{abstract}
Departments of ${ }^{1}$ Gastroenterology and Hepathology and ${ }^{2}$ Pathology, Hospital Universitario de la Princesa, Universidad Autónoma de Madrid (UAM), C/Diego de León 62, 28006 Madrid; Departments of ${ }^{3}$ Biostatistics and Epidemiology and ${ }^{4}$ Surgery, School of Medicine, UAM, C/Arzobispo Morcillo s/n, 28049 Madrid; ${ }^{5}$ Centro de Investigación Biomédica en Red de Enfermedades Hepáticas y Digestivas (CIBEREHD), ${ }^{6}$ Department of Oncology, Hospital Universitario Ramón y Cajal, UAM, Ctra. Colmenar Viejo, Km 9, 10028034 Madrid, Spain
\end{abstract}

Received September 18, 2009; Accepted November 12, 2009

DOI: $10.3892 /$ or_00000776

\begin{abstract}
Experimental evidence has revealed that several thymidylate synthase (TS) DNA polymorphisms modulate gene expression, which, in turn is known to be downregulated by oestrogen receptor subtypes. Consequently, this process might be influenced by female hormones. Based on these data, we investigated whether patient's gender and TS polymorphism exert an interactive effect on the clinical evolution of patients with advanced colorectal cancer (CRC) subjected to 5 fluorouracil (5FU)-based adjuvant chemotherapy. A retrospective study was carried out on paraffinembedded sections from $81 \mathrm{CRC}$ patients. A variable tandem repeat (VNTR) of $28 \mathrm{bp}$, a G/C single nucleotide polymorphism (SNP), and a deletion of 6 bp (ins1494del 6 bp) were studied. Genotyping methods were polymerase chain reaction (PCR) for VNTR, and PCR followed by restriction length fragment polymorphism (PCR-RFLP) for SNP and ins1494del $6 \mathrm{bp}$. The effect of TS genotype and gender on overall and progression-free survival was assessed in univariate and multivariate (Cox regression model) tests. In male patients, the study of combined TS genotypes showed that $\mathrm{G} \& 6^{+} / 6^{+}$ was an adverse marker for overall $(\mathrm{P}=0.04$; median: not reached) and progression-free survival $(\mathrm{P}=0.03$; median: 12 months, 95\% CI: 0-32.4). In the multivariate analysis, the
\end{abstract}

Correspondence to: Dr María-Encarnación Fernández-Contreras, Department of Gastroenterology and Hepathology, Hospital Universitario de la Princesa, Universidad Autónoma de Madrid (UAM), C/Diego de León 62, 28006 Madrid, Spain

E-mail: efernandezc.hlpr@salud.madrid.org

Key words: thymidylate synthase, gender, DNA polymorphism, prognosis, colorectal cancer concurrence of $\mathrm{G} \& 6^{+} / 6^{+}$combination and male patients resulted in a 5.5 -fold increased risk of relapse or disease progression (95\% CI: 1-32.1; likelihood test $\mathrm{P}=0.004$; interaction $\mathrm{P}=0.06$ ). TS genotype did not affect survival among women. The present study supports that the effect of TS polymorphisms on the clinical evolution of advanced CRC patients is significantly influenced by gender.

\section{Introduction}

A number of studies have explored the possible effect of DNA polymorphisms within the thymidylate synthase (TS) gene on the clinical evolution and response to chemotherapy of patients with advanced colorectal cancer (CRC) $(1,2)$. These investigations are based on two main features: first, TS is targeted by 5 -fluorouracil $(5 \mathrm{FU})$ and its derivatives, which are the treatment of choice in chemotherapeutic regimens of CRC and other tumours; and second, TS gene polymorphisms have shown in vitro to affect the expression of the enzyme. TS catalyzes the reductive methylation of deoxyuridylate (dUMP) to thymidylate (dTMP), which represents the only intracellular de novo source of dTMP (3). Therefore, it is essential for DNA biosynthesis and repair, and plays a central role in cell proliferation. Aside from its quality of therapeutic target, recent experimental data revealed that high TS expression and activity confer oncogenic potential to the protein $(4,5)$. Three polymorphisms affecting TS expression have been identified. A variable number of tandem repeats (VNTR) of a 28 base pairs (bp) sequence, and a single nucleotide polymorphism (SNP) are located within the 5' untranslated region (5'UTR). The VNTR gives rise primarily to alleles of two $(2 \mathrm{R})$ and three $(3 \mathrm{R})$ repeats, and the SNP consists of a $\mathrm{G} \rightarrow \mathrm{C}$ substitution at the 12 th nucleotide of the second repeat of the $3 R$ (6-9). The third polymorphism is a 6-bp deletion at position 1494, within the 3'UTR (10). In vitro studies reveal that VNTR and SNP affect translation efficiency, while ins1494del $6 \mathrm{pb}$ influences mRNA stability $(11,12)$. 
However, experimental findings do not correlate with differences regarding patient evolution in the clinical practice, and the attempts to elucidate whether survival and/or response to 5FU-based chemotherapy might have a genetic background have given rise to divergent results $(1,2,13-17)$.

Gender-related differences in CRC incidence and behaviour have been reported. The disease is less frequent in women, who also seem to be better responders than men to 5FU $(18,19)$. Furthermore, a protective effect of hormone replacement therapy has been suggested in postmenopausal women (20-22). The data point to some influence of female hormones on CRC development and, interestingly, experimental findings strongly suggest that such influence is due to an interaction with TS expression $(23,24)$. Thus, it might be hypothesized that a gender-dependent modulation could explain the inconsistent results of studies regarding TS genotype and survival mentioned above.

Differences related to gender and/or postmenopausal hormone use have been reported in risk estimations of cancer regarding TS genotype $(25,26)$, but to our knowledge, there are no data correlating both parameters with overall survival or disease progression. The aim of the present study was to investigate whether the effect of TS polymorphisms on the clinical evolution of advanced CRC patients is interfered by gender.

\section{Patients and methods}

Subjects and treatment. The identification of TS gene polymorphisms was carried out in a group of 81 patients diagnosed with advanced CRC between 1993 and 2002. They were treated by surgical resection and subjected to adjuvant chemotherapy treatment with 5FU. The chemotherapeutic agent was administered via bolus regimen in all cases. The median follow-up of living patients was 89.5 months (range: 4-148). The overall survival of patients included in the study was at least three months.

Sample collection and genotyping. Samples consisted of formalin-fixed paraffin-embedded specimens of primary tumours collected from the Archives of the Pathology Department of the University Hospital of La Princesa (Universidad Autónoma, Madrid, Spain). Data processing was carried out so that patient confidentiality was maintained.

DNA extraction. Genomic DNA was extracted from paraffinembedded tissue, as described earlier (27).

TS 5'UTR polymorphisms. VNTR and SNP polymorphisms within the 5'UTR region of TS promoter were determined respectively by specific PCR and PCR-RFLP as described earlier $(13,27)$. As stated in previous reports based on functional studies, subjects harbouring the $3 \mathrm{G}$ allele (i.e., $2 \mathrm{R} / 3 \mathrm{G}$, $3 \mathrm{G} / 3 \mathrm{G}$ and $3 \mathrm{G} / 3 \mathrm{C}$ ), reported as 5 'UTR high expressors, were grouped as $\mathrm{G}$ patients, and $2 \mathrm{R} / 2 \mathrm{R}, 2 \mathrm{R} / 3 \mathrm{C}, 3 \mathrm{C} / 3 \mathrm{C}$ as $\mathrm{C}$ patients (5'UTR low expressers) $(9,13,28)$.

3'UTR polymorphism. The 6-bp deletion at position 1494 of the 3'UTR region was determined by a PCR-RFLP method based on that reported by Ulrich et al (10), with slight modifications, as previously described (29).
PCR was carried out in a GeneAmp PCR System 2700 (Applied Biosystems, Foster City, CA, USA). All PCR primers were provided by Metabion International AG (Martinsried, Germany). The remaining PCR reagents were supplied by Biotools B\&M Labs, and restriction endonucleases were supplied by MP Biomedicals (Irvine, CA, USA).

Definition of TS5' and 3'UTR combined genotypes. Three groupings of TS5' and 3'UTR genotypes were considered for the present study: the first description proposed by Kawakami et al (28), based on the level of TS expression ascribed to TS5' and 3'UTR genotypes, and two more proposed by our group in a previous study, considering respectively, the presence of the variant $6^{-}$allele and the presence of at least one low expression allele in either $5^{\prime}$ or $3^{\prime} \mathrm{UTR}$. The latter two classifications are supported by previous survival data (29).

The TS expression-based classification defines four categories, namely, C\&allele 6- (5'UTRLow/3'UTRLow); C\&6+/6+ (5'UTRLow/3'UTRHigh); G\&allele 6- (5'UTRHigh/ 3'UTRLow) and G\&6+/6+ (5'UTRHigh/3'UTRHigh). High and low TS5'UTR expressers have been defined above and low TS3'UTR expressors are patients harbouring the 6- allele. The second classification clusters the combinations carrying the variant $6^{-}$allele, which results in three groups $\left(\mathrm{C} \& 6^{+} / 6^{+}\right.$, $\mathrm{G} \& 6^{+} / 6^{+}$and $\mathrm{G}$ or C\&allele $6^{-}$). Finally, the last classification considers the presence of at least one low expression genotype in either $5^{\prime}$ or $3^{\prime} \mathrm{UTR}$, leading to two categories: G\& $6^{+} / 6^{+}$ and $\left(\mathrm{C}\right.$ or $\left.6^{-}\right)$carriers.

Statistical analysis. The end-point of the study was overall survival, calculated from the start of treatment to the date of last follow-up or death. In order to compare quantitative variables, to explore associations between variables within each genotype, and to study the potential association between baseline characteristics and genotype, we used parametric tests (Student's t-test or ANOVA) or their equivalent nonparametric tests (U Mann-Whitney, Kruskall Wallis) when normality did not hold. The normality of continuous variables was checked with the Kolmogorov-Smirnov test. In order to compare categorical variables and response percentages with their 95\% CIs among genotype groups, we used the twosided Fisher's exact test or the $\chi^{2}$ test.

The association of risk factors with time-to-event endpoints was analyzed with the two-sided log-rank test, and the Kaplan-Meier (30) method was used to plot the corresponding time-to-progression and survival curves. Lost during clinical follow-up and death from unrelated causes were considered as censoring events. A univariate Cox regression analysis, with hazard ratios and their $95 \%$ CIs was used to assess the association between each potential prognostic factor and survival and time to progression. These factors were then included in a multivariate Cox proportional hazards regression model to evaluate the independent significance of each variable on survival and time to progression. The likelihood ratio test was used to assess the goodness of fit, and the Wald's test was used to assess the coefficient significance.

Two-sided P-values of $<0.05$ were considered significant. To verify the agreement of the observed genotype frequencies with those expected, according to the Hardy-Weinberg 
Table I. Baseline characteristics of patients.

\begin{tabular}{|c|c|c|c|c|}
\hline & $\begin{array}{l}\text { All patients } \\
\quad(\mathrm{n}=81)\end{array}$ & Female $(n=42)$ & Male $(n=39)$ & P-value \\
\hline Age (years, median, range) ${ }^{\mathrm{a}}$ & $64(39-84)$ & $63.5(41-84)$ & $64(39-84)$ & 0.96 \\
\hline OS (months, median, range) ${ }^{\mathrm{a}}$ & $76(3-148)$ & $85.5(5-148)$ & $72(3-148)$ & 0.34 \\
\hline PFS (months, median, range) & $36(2-148)$ & $47 \quad(2-148)$ & $33(3-144)$ & 0.16 \\
\hline \multicolumn{5}{|l|}{ Dukes stage, n (\%) } \\
\hline B2 & $34 \quad(42.0)$ & $(47.6)$ & $14 \quad(35.9)$ & 0.22 \\
\hline $\mathrm{C}$ & $34 \quad(42.0)$ & $(42.9)$ & $16 \quad(41.1)$ & \\
\hline $\mathrm{D}$ & $13 \quad(16.0)$ & $(9.5)$ & $9 \quad(23.1)$ & \\
\hline \multicolumn{5}{|l|}{ Tumour location, $\mathrm{n}(\%)$} \\
\hline Right & $27 \quad(33.3)$ & $(23.8)$ & $17 \quad(43.6)$ & 0.17 \\
\hline Transverse & $(2.4)$ & $(2.4)$ & (2.6) & \\
\hline Left & $30 \quad(37.0)$ & $(47.6)$ & $10 \quad(25.6)$ & \\
\hline Rectum & $22 \quad(27.2)$ & $(26.2)$ & $11 \quad(28.2)$ & \\
\hline \multicolumn{5}{|l|}{ Mortality, n (\%) } \\
\hline Alive & $43 \quad(53.1)$ & $(57.1)$ & $19 \quad(48.7)$ & 0.57 \\
\hline Dead of CRC & $17 \quad(21.0)$ & $(16.7)$ & $10 \quad(25.6)$ & \\
\hline Dead of unrelated cause & $(1.2)$ & $(2.4)$ & 0 & \\
\hline Lost & $20 \quad(24.7)$ & $(23.8)$ & $10 \quad(25.6)$ & \\
\hline \multicolumn{5}{|l|}{ Relapse, n (\%) } \\
\hline No & $30 \quad(37.0)$ & $(45.2)$ & $11 \quad(28.2)$ & 0.28 \\
\hline Yes & $40 \quad(49.4)$ & $(42.9)$ & $22 \quad(56.4)$ & \\
\hline Lost & $11 \quad(13.6)$ & $(11.9)$ & $6 \quad(15.4)$ & \\
\hline
\end{tabular}

aANOVA; OS, overall survival; PFS, progression-free survival.

equilibrium model (31), the likelihood-ratio test G was used. All statistical calculations were performed with the SPSS software statistical package, version 14.0 (SPSS, Inc., Chicago, IL, USA).

\section{Results}

Patient characteristics are shown in Table I. Median age was 64 years (range: $39-84)$. There were 42 females $(51.9 \%)$ and 39 males $(48.1 \%)$. The median age of female patients was 63.5 years (range: $41-84$ ) and 37 were $>50$ years old $(88.1 \%$ ).

TS genotype frequencies. Genotype distributions of VNTR, $\mathrm{SNP} \mathrm{G} / \mathrm{C}$, ins/del 6 bp polymorphisms, and their combinations (TS expression-based classification) are summarized in Table II. VNTR, SNP G/C and ins/del 6 bp genotyping were feasible in $81(100 \%), 80(98.8 \%)$ and $79(97.5 \%)$ patients respectively. The frequencies of VNTR and ins/del 6 bp genotypes were in agreement with those expected according to the Hardy-Weinberg equilibrium model.

Univariate survival analyses. The results of the Kaplan-Meier and Cox regression univariate analyses are summarized in Tables III and IV. In men, a significant association between SNP G\& $6^{+} / 6^{+}$and poorer PFS was observed, regardless of the criteria for defining TS genotype combinations (median: 12 months; 95\% CI: 0-32; Cox regression $\mathrm{P}=0.01$ ). This effect was stronger when comparing patients with this genotype vs. those with combinations carrying either the $\mathrm{C}$ genotype or the allele 6- (log-rank $\mathrm{P}=0.003$, Table III; Cox regression $\mathrm{P}=0.007$, Table IV); the influence on $\mathrm{OS}$ reached statistical signification (log-rank $\mathrm{P}=0.04$, Table III; Cox regression $\mathrm{P}=0.05$, Table IV). The Kaplan-Meier analysis revealed a slight trend to better PFS of male $\mathrm{C}$ patients, compared to $\mathrm{G}$ (median: not reached vs. 22.0 months; $95 \%$ CI: 2.8-41.2), although statistical signification was not achieved (log-rank $\mathrm{P}=0.09$, Cox regression $\mathrm{P}=0.1$ ). TS genotype did not affect survival of women.

Fig. 1 shows the PFS plots obtained for male and female patients with $\mathrm{G} \& 6^{+} / 6^{+}$genotype (log-rank $\left.\mathrm{P}=0.01\right)$. Similar survival analyses stratified by TS combined genotype were performed considering all the proposed classifications. No differences between men and women were observed. Although P-value was 0.48 , the PFS graph obtained for the $C \& 6^{+} / 6^{+}$ group suggested a slight visual trend to better outcome for the female patients (data not shown).

There were five women and six men with $\mathrm{G} \& 6^{+} / 6^{+}$polymorphisms; their tumour stages, PFS values and number of disease relapses/progressions are listed in Table V. Two 
Table II. Thymidylate synthase (TS) genotype distribution among female and male patients.

\begin{tabular}{|c|c|c|c|c|}
\hline TS genotype & $\begin{array}{c}\text { All patients } \\
\text { n }(\%)\end{array}$ & $\begin{array}{c}\text { Female } \\
\mathrm{n}(\%)\end{array}$ & $\begin{array}{l}\text { Male } \\
\mathrm{n}(\%)\end{array}$ & P-value \\
\hline \multicolumn{5}{|l|}{ VNTR } \\
\hline $3 R / 3 R$ & $20(24.7)$ & $13(31.9)$ & $7(17.9)$ & 0.39 \\
\hline $2 \mathrm{R} / 3 \mathrm{R}$ & $45(55.6)$ & $21(50.0)$ & $24(61.5)$ & \\
\hline $2 \mathrm{R} / 2 \mathrm{R}$ & $16(19.8)$ & $8(19.0)$ & $8(20.5)$ & \\
\hline \multicolumn{5}{|l|}{ SNP } \\
\hline G & $40(50.0)$ & $21(50.0)$ & $19(50.0)$ & 0.59 \\
\hline $\mathrm{C}$ & $40(50.0)$ & $21(50.0)$ & $19(50.0)$ & \\
\hline \multicolumn{5}{|l|}{ Ins/del 6 bp } \\
\hline $6^{+} / 6^{+}$ & $34(43.0)$ & $18(42.9)$ & $16(43.2)$ & 0.78 \\
\hline $6^{+} / 6^{-}$ & $39(49.4)$ & $20(47.6)$ & 19 (51.4) & \\
\hline $6^{-} / 6^{-}$ & $6 \quad(7.6)$ & $4 \quad(9.5)$ & $2 \quad(5.4)$ & \\
\hline \multicolumn{5}{|l|}{ SNP\&ins/del 6 bp } \\
\hline C\&allele 6- & $16(20.3)$ & $8(19.0)$ & 8 (21.6) & 0.92 \\
\hline $\mathrm{C} \& 6^{+} / 6^{+}$ & $23(29.1)$ & $13(31.0)$ & $10(27.0)$ & \\
\hline G\&allele 6 & $29(36.7)$ & $16(38.1)$ & $13(35.1)$ & \\
\hline $\mathrm{G} \& 6^{+} / 6^{+}$ & $11(13.9)$ & $5(11.9)$ & $6(16.2)$ & \\
\hline \multicolumn{5}{|c|}{ SNP\&presence of allele $6^{-}$} \\
\hline $\mathrm{C} \& 6^{+} / 6^{+}$ & $23(29.1)$ & $24(57.1)$ & $21(56.8)$ & 0.75 \\
\hline$(\mathrm{G}$ or $\mathrm{C}) \&$ allele $6^{-}$ & $45(57.0)$ & $13(31.0)$ & $10(27.0)$ & \\
\hline $\mathrm{G} \& 6^{+} / 6^{+}$ & $11(13.9)$ & $5(11.9)$ & $6(16.2)$ & \\
\hline \multicolumn{5}{|c|}{ G\& $6^{+} / 6^{+}$vs. (C or $6^{-}$carriers $)$} \\
\hline$\left(\mathrm{C}\right.$ or $\left.6^{-}\right)$carriers & $68(86.1)$ & $37(88.1)$ & $31(83.8)$ & 0.92 \\
\hline $\mathrm{G} \& 6^{+} / 6^{+}$ & $11(13.9)$ & $5(11.9)$ & $6(16.2)$ & \\
\hline
\end{tabular}

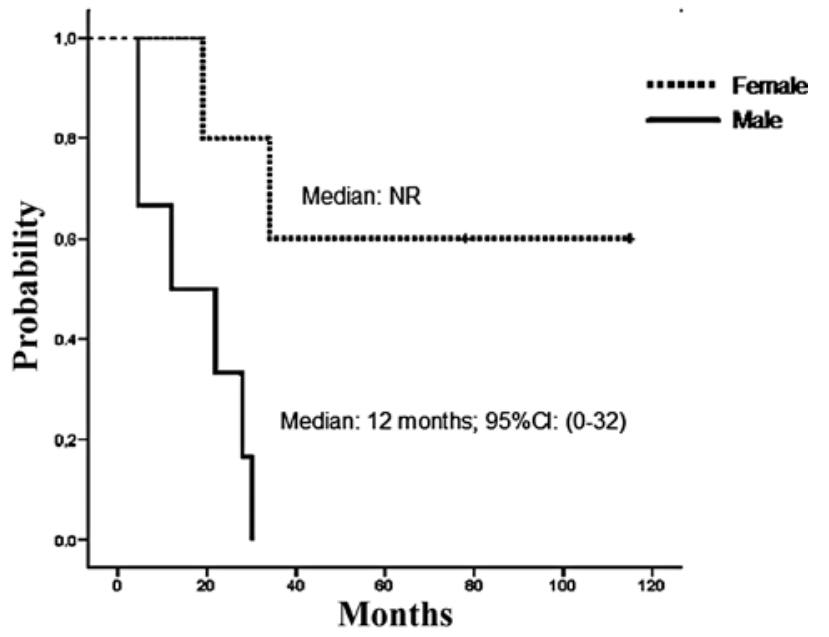

Figure 1. Progression-free survival of $\mathrm{G \&} 6^{+} / 6^{+}$female and male patients (logrank $\mathrm{P}=0.01)(\mathrm{NR}$, not reached; $\mathrm{CI}$, confidence interval).

women within this group relapsed; one of them was diagnosed as $\mathrm{B} 2$ tumour stage, the remaining being $\mathrm{C}$ stages. All G\&6+/ $6^{+}$males underwent disease relapse or progression; half of them $(n=3)$ were in B2 stage.
Multivariate survival analysis. In order to test the possible influence of interactions between gender and TS genotype on survival, risk ratios were estimated from Cox proportional hazards regression models. When PFS was analyzed considering $\mathrm{G} \& 6^{+} / 6^{+}$patients vs. (SNP C or allele $6^{-}$) carriers, the interaction between gender and genotype was borderline to statistical signification (interaction $\mathrm{P}=0.06$ ) (Table VI). The relative risk of relapse or disease progression in male $\mathrm{G} \& 6^{+} /$ $6^{+}$patients was 5.5 (95\% CI: $1-32.1$; likelihood test $\left.\mathrm{P}=0.004\right)$. The same study with separate TS genotypes or other combinations related to PFS or OS failed to show other associations (data not shown).

\section{Discussion}

The interaction of ERß with TS expression has been documented in previous literature. Oestrogen receptor- $\beta$ (ERß) has shown in vitro to decrease TS expression (23). In vivo, significantly higher TS levels have been detected in ER-negative tissues from various malignancies $(24,32)$, compared to ER positive tissues. However, similarly to the reported studies concerning $T S$ gene polymorphisms, the effect of ERß on TS expression in vivo is not very clear (23). Given the above data, it is reasonable to presume that 
Table III. Univariate Kaplan-Meier analysis of the effect of thymidylate synthase (TS) genotype on overall and progressionfree survival.

\begin{tabular}{|c|c|c|c|c|c|c|}
\hline \multirow[b]{2}{*}{ TS polymorphism } & \multicolumn{3}{|c|}{ OS (months) } & \multicolumn{3}{|c|}{ PFS (months) } \\
\hline & Median & $95 \% \mathrm{CI}$ & P-value & Median & $95 \%$ CI & P-value \\
\hline \multicolumn{7}{|l|}{ VNTR } \\
\hline Female $(n=42)$ & NR & - & 0.35 & NR & - & 0.88 \\
\hline Male $(n=39)$ & NR & - & 0.47 & 36.0 & $20.0-52.0$ & 0.18 \\
\hline \multicolumn{7}{|l|}{ SNP } \\
\hline Female $(n=42)$ & NR & - & 0.32 & NR & - & 0.96 \\
\hline Male $(\mathrm{n}=38)$ & NR & - & 0.1 & 40.0 & $23.2-56.8$ & 0.09 \\
\hline \multicolumn{7}{|l|}{ Ins/del $6 b^{a}$} \\
\hline Female $(n=42)$ & NR & - & 0.29 & NR & - & 0.16 \\
\hline Male $(n=37)$ & NR & - & 0.88 & 36.0 & 20.5-51.6 & 0.48 \\
\hline \multicolumn{7}{|l|}{ SNP\&ins/del 6 bp } \\
\hline Female $(\mathrm{n}=42)$ & NR & - & 0.32 & NR & - & 0.37 \\
\hline Male $(\mathrm{n}=37)$ & NR & - & 0.16 & 36.0 & $20.5-51.6$ & 0.03 \\
\hline \multicolumn{7}{|c|}{ SNP\&presence of allele 6} \\
\hline Female $(n=42)$ & NR & - & 0.45 & NR & - & 0.37 \\
\hline Male $(n=37)$ & NR & - & 0.07 & 36.0 & $20.5-51.6$ & 0.01 \\
\hline \multicolumn{7}{|c|}{$\mathrm{G} \& 6^{+} / 6^{+}$vs. (C or $6^{-}$carriers $)$} \\
\hline Female $(n=42)$ & NR & - & 0.29 & NR & - & 0.72 \\
\hline Male $(n=37)$ & NR & - & 0.04 & 36.0 & $20.5-51.6$ & 0.003 \\
\hline
\end{tabular}

${ }^{\mathrm{a}} 6^{+} / 6^{+}$vs. allele 6 ; OS, overall survival; PFS, progression-free survival.

inconsistent observations regarding the effects of either $T S$ genotype or ER expression in the clinical setting could be due to a veiled interference of gender in studies on DNA polymorphism and, conversely, of TS genotype in studies on ER.

TS genotype frequencies found in our study did not diverge between genders and were consistent with those reported for Caucasian populations $(7,25)$.

Our previous observations, including this series of patients (29), revealed that TS 5' (VNTR, SNP G/C) and TS3' UTR (ins1494del $6 \mathrm{bp}$ ) polymorphisms alone did not affect overall or progression-free survival, but SNP C\& $6^{+} / 6^{+}$and SNP $\mathrm{G} \& 6^{+} / 6^{+}$genotype combinations determined respectively, the best and worst evolution, the latter showing significantly shorter PFS than $C \& 6^{+} / 6^{+}$.

In the present study, the Kaplan-Meier and Cox univariate analyses were stratified by gender. Results revealed that our preliminary data, pointing to an adverse influence of $\mathrm{G} \& 6^{+} / 6^{+}$combined genotype on PFS, were true for men, but not for women, with the exception of a slight trend to better evolution of females within the 'favourable' $\mathrm{C} \& 6^{+} / 6^{+}$group, observed in the Kaplan-Meier plot. The poor outcome associated to $\mathrm{G} \& 6^{+} / 6^{+}$combination was independent of the criteria used for defining TS combined genotypes. Moreover, when male $\mathrm{G} \& 6^{+} / 6^{+}$patients were compared to (C or $6^{-}$) carriers, significant differences were observed also for OS. A slight influence of SNP alone on survival was seen in men, although under the threshold of statistical significance. In contrast, TS genotype did not affect the evolution of female patients.

The PFS plot shown in Fig. 1 illustrates the dramatically different behaviour of male and female patients harbouring the adverse $\mathrm{G} \& 6^{+} / 6^{+}$combination. Such differences are not attributable to divergences in sample size or tumour stage. The proportion of females with $\mathrm{G} \& 6^{+} / 6^{+}$combination genotype is equivalent to that of males (five women vs. six men). Yet, the rates of relapse/disease progression were different: all male patients relapsed or underwent disease progression between 5 and 30 months; meanwhile, the two events observed among women took place at 19 and 34 months, respectively, and the maximum PFS period reached 115 months. Neither the number of relapses, nor the striking divergences in PFS plots can be ascribed to tumour stage because, though there were two men vs. no women classified as D stages, half of male patients were B2 vs. one female. Noteworthy, this patient was one of the two who relapsed within the group of women.

These findings suggested an interaction of gender with TS genotype that affected PFS, and warranted a multivariate analysis for confirmation. The Cox regression model 
Table IV. Univariate Cox analysis of the effect of thymidylate synthase (TS) genotype on overall and progression-free survival.

\begin{tabular}{|c|c|c|c|c|c|c|c|c|c|c|c|c|}
\hline \multirow[b]{3}{*}{ TS polymorphism } & \multicolumn{6}{|c|}{ OS } & \multicolumn{6}{|c|}{ PFS } \\
\hline & \multicolumn{3}{|c|}{ Female } & \multicolumn{3}{|c|}{ Male } & \multicolumn{3}{|c|}{ Female } & \multicolumn{3}{|c|}{ Male } \\
\hline & P-value & HR & $95 \% \mathrm{CI}$ & P-value & HR & $95 \% \mathrm{CI}$ & P-value & HR & $95 \% \mathrm{CI}$ & P-value & HR & $95 \% \mathrm{CI}$ \\
\hline \multicolumn{13}{|l|}{ VNTR } \\
\hline $3 R / 3 R$ & - & 1 & - & - & 1 & - & - & 1 & - & - & 1 & - \\
\hline $2 \mathrm{R} / 2 \mathrm{R}$ & 0.71 & 1.69 & $0.11-26.94$ & 0.87 & 0.80 & $0.05-12.81$ & 0.62 & 0.71 & $0.18-2.83$ & 0.83 & 1.22 & $0.20-7.30$ \\
\hline $2 \mathrm{R} / 3 \mathrm{R}$ & 0.21 & 3.90 & $0.45-33.51$ & 0.44 & 2.27 & $0.20-18.18$ & 0.84 & 0.90 & $0.32-2.52$ & 0.18 & 2.75 & $0.63-11.95$ \\
\hline \multicolumn{13}{|l|}{ SNP } \\
\hline $\mathrm{C}$ & - & 1 & - & - & 1 & - & - & 1 & - & - & 1 & - \\
\hline $\mathrm{G}$ & 0.33 & 0.44 & $0.09-2.30$ & 0.11 & 2.98 & $0.77-11.58$ & 0.96 & 1.02 & $0.41-2.59$ & 0.10 & 2.06 & $0.86-4.92$ \\
\hline \multicolumn{13}{|l|}{ Ins/del $6 b^{a}$} \\
\hline $6^{+} / 6^{+}$ & - & 1 & - & - & 1 & - & - & 1 & - & - & 1 & - \\
\hline Allele $6^{-}$carrier & 0.31 & 2.36 & $0.46-12.24$ & 0.88 & 0.91 & $0.26-3.16$ & 0.17 & 1.98 & $0.74-5.30$ & 0.49 & 0.74 & $0.31-1.74$ \\
\hline \multicolumn{13}{|l|}{ SNP\&ins/del 6 bp } \\
\hline $\mathrm{C} \& 6^{+} / 6^{+}$ & - & 1 & - & - & 1 & - & - & 1 & - & - & 1 & - \\
\hline C\&allele 6- & 0.24 & 2.91 & $0.49-17.44$ & 0.39 & 2.87 & $0.26-31.67$ & 0.10 & 3.01 & $0.81-11.25$ & 0.79 & 1.20 & $0.32-4.49$ \\
\hline G\&allele 6- & 0.97 & 1.04 & $0.15-7.40$ & 0.31 & 3.22 & $0.33-31.11$ & 0.37 & 1.78 & $0.52-6.08$ & 0.62 & 1.36 & $0.41-4.45$ \\
\hline $\mathrm{G} \& 6^{+} 6^{+}$ & 0.99 & 0 & - & 0.06 & 8.12 & $0.91-72.89$ & 0.78 & 1.28 & $0.23-7.00$ & 0.01 & 4.87 & $1.38-17.16$ \\
\hline \multicolumn{13}{|l|}{$\begin{array}{l}\text { SNP\&presence of } \\
\text { allele } 6^{-}\end{array}$} \\
\hline $\mathrm{C} \& 6^{+} / 6^{+}$ & - & 1 & - & - & 1 & - & - & 1 & - & - & 1 & - \\
\hline$(\mathrm{G}$ or $\mathrm{C}) \&$ & 0.53 & 1.69 & $0.33-8.77$ & 0.31 & 3.07 & $0.36-26.35$ & 0.19 & 2.14 & $0.69-6.66$ & 0.64 & 1.29 & $0.44-3.78$ \\
\hline \multicolumn{13}{|l|}{$\mathrm{G} \& 6^{+} / 6^{+}$vs. (C } \\
\hline \multicolumn{13}{|l|}{ or 6- carriers) } \\
\hline $\mathrm{G} \& 6^{+} / 6^{+}$ & - & 1 & - & - & 1 & - & - & 1 & - & - & 1 & - \\
\hline$\left(\mathrm{C}\right.$ or $\left.6^{-}\right)$carriers & 0.5 & 0.04 & $0-472.52$ & 0.05 & 3.56 & $1.00-12.62$ & 0.73 & 0.77 & $0.18-3.36$ & 0.007 & 4.13 & $1.48-11.49$ \\
\hline
\end{tabular}

Table V. Number of relapsed and progression-free survival (PFS) period of $\mathrm{G \&} 6^{+} / 6^{+}$patients.

\begin{tabular}{|c|c|c|c|c|c|c|c|}
\hline \multicolumn{4}{|c|}{ Female } & \multicolumn{4}{|c|}{ Male } \\
\hline Patient & Dukes stage & Relapse/Progression & PFS (months) & Patient & Dukes stage & Relapse/Progression & PFS (months) \\
\hline 1 & $\mathrm{C}$ & Yes & 19 & 1 & $\mathrm{C}$ & Yes & 5 \\
\hline 2 & $\mathrm{~B} 2$ & Yes & 34 & 2 & $\mathrm{D}$ & Yes & 5 \\
\hline 3 & $\mathrm{C}$ & No & 78 & 3 & B2 & Yes & 12 \\
\hline 4 & $\mathrm{C}$ & No & 115 & 4 & B2 & Yes & 22 \\
\hline \multirow[t]{2}{*}{5} & $\mathrm{C}$ & No & 115 & 5 & $\mathrm{D}$ & Yes & 28 \\
\hline & & & & 6 & B2 & Yes & 30 \\
\hline
\end{tabular}

indicated an interactive effect of both parameters borderline to statistical signification. The concurrence of male patients and $\mathrm{G} \& 6^{+} / 6^{+}$combination determined 5.5-fold higher risk of relapse or disease progression. This result might be explained by the down-regulatory effect of ER on TS expression. Both SNP G and $6^{+} / 6^{+}$polymorphisms lead to increased TS levels, 
Table VI. Multivariate Cox regression analysis for risk of relapse associated with gender and combined TS genotype $\left[\left(\mathrm{C}\right.\right.$ or allele $\left.6^{-}\right)$vs. $\left.\mathrm{G} \& 6^{+} / 6^{+}\right]$. Likelihood test $\mathrm{P}=0.004$.

\begin{tabular}{lccr}
\hline Marker & P-value & HR & 95\% CI \\
\hline Gender & 0.7 & 1.2 & $0.6-2.3$ \\
Combined TS genotype & 0.7 & 0.8 & $0.2-3.3$ \\
Gender and combined TS genotype & 0.06 & 5.5 & $1-32.1$ \\
\hline
\end{tabular}

HR, hazard ratio; CI, confidence interval.

which in turn, have been associated to both poor response to $5 \mathrm{FU}$-based chemotherapy and to oncogenicity $(4,5)$. However, the 'adverse' phenotype associated with the G\&6+/ $6^{+}$high expression combination might be 'silenced' or, at least, reduced in the presence of ER, which has been postulated to act as a tumour suppressor gene (33). The consequence is that the predictive/ prognostic value proposed in the literature for TS genotype might be true for men but not for women.

Our study has several limitations. First, the margins of the 95\% CI obtained in the estimation of the RR of relapse for the interaction of gender and TS combined genotype are very wide (1-32.1 months). This is presumably explained by a small sample size and a low number of events. The P-value $(\mathrm{P}=0.06)$ was borderline to the threshold of statistical significance. Even so, the values corresponding to the goodness of fit to the model and to the likelihood test $(\mathrm{P}=0.04$ and $\mathrm{P}=0.004$ respectively), strongly suggest an interaction between gender and TS combined genotype that might be significant in larger studies.

Second, data regarding the hormonal status of our female patients was not available. As most of them were postmenopausal ( $88.1 \%$ were older than 50 years), divergences from men based on physiological ER levels were not expected. However, previous history of hormone replacement use, that might explain such differences, was unknown. The protective effect of hormone replacement therapy against CRC is well documented (20-22), but information about hormonal status and/or use of postmenopausal hormone is not always accessible to researchers (34).

Finally, ER expression in tumour and normal tissue was not analyzed. The effects on TS expression have been observed for ERß, but only ER $\alpha$ is currently tested in histopathology laboratories (35) to study tumours like breast cancer. The effect of ER $\alpha$ is opposite to the antiproliferative action of ERß (34) and information regarding its expression in CRC is even scarcer than that available for the latter. In addition, gene polymorphisms within ER $\alpha$ gene have been recently associated with the development of microsatellite unstable colorectal tumours and might affect ER expression (36). The task of determining ERß expression is not any easier, and is further complicated by the disclosure of at least five isoforms of this subtype $(23,37)$. Among them, ERß1 is proposed as the one able to activate oestrogen responsive elements, but little is known about the functional effect of the others. Nüssler et al (34) have recently reported differential expression of $E R \alpha$ and ERß subtypes in normal and tumour mucosa in CRC patients, with significant divergences in men, but not in women. They postulate that gender-specific differences in the pathogenesis of $C R C$ are due to $E R \alpha / E R \beta$ ratio, rather than to a separate ER subtype, though ERß level directly correlated with the degree of tumour differentiation in male patients. Our results suggest that measurements of ER expression might greatly improve the predictive value of TS genotyping and vice versa, but consensus regarding analyzed parameters (i.e., subtypes, ratio, isoforms) and methodology should be achieved first.

Patient's gender has been reported to affect the risk of developing CRC attributed to several TS genotypes. A decrease in CRC risk associated to $2 \mathrm{R} / 2 \mathrm{R}$ genotype in male patients has been described. Concerning females, genotype combinations including $2 \mathrm{R}$ and $6^{-}$alleles showed a protective effect in stage IV patients, and in postmenopausal hormone users $(16,25,38)$. However, to our knowledge, this is the first study to document the interactive effect of patient's gender and TS genotype on survival. The data reported herein should be confirmed in large-scale investigations, because the interaction between TS genotype and gender, in terms of reproductive hormonal status, might have important prognostic and therapeutic implications.

\section{Acknowledgements}

We thank Ms. Joanna Bejarano for her invaluable help in improving the English. This study was supported by a grant from the Program COLOMICS (S-GEN-0266-2006) of R+D Activities among Biosciences Research Groups from the Autonomous Community of Madrid (Foundation for Biomedical Research, Hospital Universitario de la Princesa).

\section{References}

1. Locker GY, Hamilton S, Harris J, et al: ASCO 2006 update of recommendations for the use of tumor markers in gastrointestinal cancer. J Clin Oncol 24: 5313-5327, 2006.

2. Gusella M and Padrini R: G/C SNP of thymidylate synthase with respect to colorectal cancer. Pharmacogenomics 8: 985-996, 2007.

3. Van Triest B and Peters GJ: Thymidylate synthase: a target for combination therapy and determinant of chemotherapeutic response in colorectal cancer. Oncology 57: 179-194, 1999.

4. Rahman L, Voeller D, Rahman M, et al: Thymidylate synthase as an oncogene: a novel role for an essential DNA synthesis enzyme. Cancer Cell 5: 341-351, 2004.

5. Chen M, Rahman L, Voeller D, et al: Transgenic expression of human thymidylate synthase accelerates the development of hyperplasia and tumors in the endocrine pancreas. Oncogene 26: 4817-4824, 2007.

6. Horie N, Aiba H, Oguro K, Hojo H and Takeishi K: Functional analysis and DNA polymorphism on the tandemly repeated sequences in the 5'-terminal regulatory region of the human gene for thymidylate synthase. Cell Struct Funct 20: 191-197, 1995.

7. Marsh S: Thymidylate synthase pharmacogenetics. Invest New Drugs 23: 533-537, 2005.

8. Kawakami K, Salonga D, Park JM, et al: Different lengths of a polymorphic repeat sequence in the thymidylate synthase gene affect translational efficiency but not its gene expression. Clin Cancer Res 7: 4096-4101, 2001.

9. Mandola MV, Stoehlmacher J, Muller-Weeks S, Cesarone G, Yu MC, Lenz HJ and Ladner RD: A novel single nucleotide polymorphism within the 5 ' tandem repeat polymorphism of the thymidylate synthase gene abolishes USF-1 binding and alters transcriptional activity. Cancer Res 63: 2898-2904, 2003. 
10. Ulrich CM, Bigler J, Velicer CM, Greene EA, Farin FM and Potter JD: Searching expressed sequence tag databases: discovery and confirmation of a common polymorphism in the thymidylate synthase gene. Cancer Epidemiol Biomarkers Prev 9: $1381-1385,2000$

11. Mandola MV, Stoehlmacher J, Zhang W, et al: A 6 bp polymorphism in the thymidylate synthase gene causes message instability and is associated with decreased intratumoral TS mRNA levels. Pharmacogenetics 14: 319-322, 2004.

12. Pullmann R Jr, Abdelmohsen K, Lal A, Martindale JL, Ladner RD and Gorospe M: Differential stability of thymidylate synthase 3'-untranslated region polymorphic variants regulated by AUF1. J Biol Chem 281: 23456-23463, 2006.

13. Kawakami K and Watanabe G: Identification and functional analysis of a single nucleotide polymorphism in the tandem repeat sequence of thymidylate synthase gene. Cancer Res 63: 6004-6007, 2003.

14. Marcuello E, Altes A, Del Rio E, Cesar A, Menoyo A and Baiget M: Single nucleotide polymorphism in the $5^{\prime}$ tandem repeat sequences of thymidylate synthase gene predicts for response to fluorouracil-based chemotherapy in advanced colorectal cancer patients. Int J Cancer 112: 733-737, 2004.

15. Lecompte T, Ferraz JM, Zinzindohoué F, et al: Thymidylate synthase gene polymorphism predicts toxicity in colorectal cancer patients receiving 5-fluorouracil-based chemotherapy. Clin Cancer Res 10: 5880-5888, 2004.

16. Chen J, Hunter DJ, Stampfer MJ, et al: Polymorphism in the thymidylate synthase promoter enhancer region modifies the risk and survival of colorectal cancer. Cancer Epidemiol Biomarkers Prev 12: 958-962, 2003

17. Dotor E, Cuatrecases M, Martinez-Iniesta M, et al: Tumor thymidylate synthase 1494del6 genotype as a prognostic factor in colorectal cancer patients receiving fluorouracil-based adjuvant treatment. J Clin Oncol 24: 1603-1611, 2006

18. DeCosse JJ, Ngoi SS, Jacobson JS and Cennerazzo WJ: Gender and colorectal cancer. Eur J Cancer Prev 2: 105-115, 1993.

19. Elsaleh H, Joseph D, Grieu F, Zeps N, Spry N and Iacopetta B: Association of tumour site and sex with survival benefit from adjuvant chemotherapy in colorectal cancer. Lancet 355: 1745-1750, 2000 .

20. Paganini-Hill A: Estrogen replacement therapy and colorectal cancer risk in elderly women. Dis Colon Rectum 42: 1300-1305, 1999

21. Calle EE, Miracle-McMahill HL, Thun MJ and Heath CW Jr: Estrogen replacement therapy and risk of fatal colon cancer in a prospective cohort of postmenopausal women. J Natl Cancer Inst 87: 517-523, 1995.

22. Nanda K, Bastian LA, Hasselblad V and Simel DL: Hormone replacement therapy and the risk of colorectal cancer: a metaanalysis. Obstet Gynecol 93: 880-888, 1999.

23. Wong NA, Malcomson RD, Jodrell DI, Groome NP, Harrison DJ and Saunders PT: ER beta isoform expression in colorectal carcinoma: an in vivo and in vitro study of clinicopathological and molecular correlates. J Pathol 207: 53-60, 2005.

24. Nakayama Y, Sakamoto H, Satoh K and Yamamoto T: Tamoxifen and gonadal steroids inhibit colon cancer growth in association with inhibition of thymidylate synthase, survivin and telomerase expression through estrogen receptor beta mediated system. Cancer Lett 161: 63-71, 2000.
25. Ulrich CM, Curtin K, Potter JD, Bigler J, Caan B and Slattery ML: Polymorphisms in the reduced folate carrier, thymidylate synthase or methionine synthase and risk of colon cancer. Cancer Epidemiol Biomarkers Prev 14: 2509-2516, 2005.

26. Zhai X, Gao J, Hu Z, et al: Polymorphisms in thymidylate synthase gene and susceptibility to breast cancer in a Chinese population: a case-control analysis. BMC Cancer 25;6: 138, 2006.

27. Fernandez-Contreras ME, Sanchez-Prudencio S, SanchezHernandez JJ, Garcia de Paredes ML, Gisbert JP, Roda-Navarro P and Gamallo C: Thymidylate synthase expression pattern, expression level and single nucleotide polymorphism are predictors for disease-free survival in patients of colorectal cancer treated with 5-fluorouracil. Int J Oncol 28: 1303-1310, 2006.

28. Kawakami K, Graziano F, Watanabe G, et al: Prognostic role of thymidylate synthase polymorphisms in gastric cancer patients treated with surgery and adjuvant chemotherapy. Clin Cancer Res 11: 3778-3783, 2005.

29. Fernández-Contreras ME, Sánchez-Hernández JJ, González E, et al: Combination of polymorphisms within $5^{\prime}$ and $3^{\prime}$ untranslated regions of thymidylate synthase gene modulates survival in 5 fluorouracil-treated colorectal cancer patients. Int $\mathbf{J}$ Oncol 34: 219-229, 2009.

30. Kaplan EL and Meier P: Non-parametric estimation from incomplete observations. J Am Stat Assoc 53: 457-481, 1958.

31. Weir BS: Disequilibrium. In: Genetic Data Analysis II: Methods for Discrete Population Genetic Data. Sinaur Associates, Sunderland, MA, pp91-139, 1996.

32. Kurebayashi J, Yamamoto Y, Udagawa K, Okubo S, Fukushima M and Sonoo H: Establishment of enzyme-linked immunosorbent assays for thymidylate synthase and dihydropyriminide dehydrogenase in cancer tissues. Oncol Rep 11: 973-979, 2004.

33. Foley EF, Jazaeri AA, Shupnik MA, Jazaeri O and Rice LW: Selective loss of estrogen receptor beta in malignant human colon. Cancer Res 60: 245-248, 2000.

34. Nüssler NC, Reinbacher K, Shanny N, et al: Sex-specific differences in the expression levels of estrogen receptor subtypes in colorectal cancer. Gend Med 5: 209-217, 2008.

35. Duffy JM: Predictive markers in breast and other cancers: a review. Clin Chem 51: 494-503, 2005.

36. Kadiyska T, Yakulov T, Kaneva R, et al: Vitamin D and estrogen receptor gene polymorphisms and the risk of colorectal cancer in Bulgaria. Int J Colorectal Dis 22: 395-400, 2007.

37. Moore JT, McKee DD, Slentz-Kesler K, et al: Cloning and characterization of human estrogen receptor beta isoforms. Biochem Biophys Res Commun 247: 75-78, 1998.

38. Curtin K, Ulrich CM, Samowitz WS, Bigler J, Caan B, Potter JD and Slattery ML: Thymidylate synthase polymorphisms and colon cancer: associations with tumor stage, tumor characteristics and survival. Int J Cancer 120: 2226-2232, 2007. 